http://jmscr.igmpublication.org/home/

ISSN (e)-2347-176x ISSN (p) 2455-0450

crossref DOI: https://dx.doi.org/10.18535/jmscr/v7i10.120

Journal Of Medical Science And Clinical Research

IGM Publication

An Official Publication of IGM Publication

\title{
Study of Fasting and Postprandial Lipid Profiles in Type 2 Diabetes Mellitus
}

\author{
Authors \\ S.Pravin $^{1 *}$, R.Aswinth ${ }^{2}$, S.Sudharsan ${ }^{3}$ \\ ${ }^{1}$ Post Graduate, ${ }^{2}$ Assistant Professor, ${ }^{3}$ Professor \\ Department of General Medicine, Rajah Muthiah Medical College Hospital, Chidambaram, \\ Tamil Nadu, India \\ *Corresponding Author
}

S.Pravin

\begin{abstract}
Background and Objectives: Type 2 diabetes mellitus is associated with the development of premature atherosclerosis and a higher cardiovascular morbidity and mortality. Diabetic dyslipidemia is believed to play an important role in the pathogenesis of accelerated atherosclerosis in this condition. It is being increasingly believed that atherosclerosis is a postprandial phenomenon as at least with respect to lipids, we are in the postprandial phase for most of the day. High postprandial triglycerides have shown a strong and independent association with CAD. Hence this study is being carried out to assess the characteristics of postprandial dyslipidaemia in types 2 diabetes mellitus in comparison with the fasting lipid levels in diabetics and controls.

Methodology: This was an observational study which included the patients admitted in Raja Muthiah Medical College Hospital, Chidambaram, Tamilnadu. The study included 50 patients with type 2 diabetes mellitus meeting the inclusion criteria and were compared with 50 age and sex matched healthy controls, fulfilling the inclusion and exclusion criteria.

Method of Collection of Data: Data for the proposed study was collected in a pretested proforma. Detailed history and physical examination of all the cases and controls was done. Fasting and Post prandial lipid levels were estimated in all the cases and controls. Blood was collected from patients after an overnight (12-hour) fast and six hour postprandial (after a standard meal) for lipid profile measurements.
\end{abstract}

Results: The majority of cases were in the age group of 61-70 years. All the cases in the fasting state had a raised triglyceride (mean $172.92 \pm 75.51 \mathrm{mg} / \mathrm{dL}$ ) level, raised VLDL-C (mean $37.76 \pm 20.01 \mathrm{mg} / \mathrm{dL}$ ) level, decreased $H D L-C$ (mean $33.44 \pm 11.99 \mathrm{mg} / \mathrm{dL}$ ) level, normal total cholesterol (mean $176.36 \pm 52.43 \mathrm{mg} / \mathrm{dL}$ ) level and normal LDL-C (mean 101.16 $\pm 38.17 \mathrm{mg} / \mathrm{dL}$ ) levels compared to the control group. In the post prandial state the diabetics had a significant increase in the post prandial triglyceride level (mean 232.52 $\pm 105.08 \mathrm{mg} / \mathrm{dL}$ ), decrease in the HDL-C level (mean $30.96 \pm 11.15 \mathrm{mg} / \mathrm{dL}$ ) compared to the fasting state whereas in the control group there was no significant increase in the post prandial lipid levels compared to the fasting state.

Conclusion: The dyslipidemia of Type 2 DM is characterised mainly of raised triglyceride levels, raised VLDL-C Levels and decreased HDL-C levels. In the post prandial state there was significant hyper-triglyceridaemia and decreased HDL-C level in diabetics when compared to that of the controls.

Keywords: Dyslipidemia, atherosclerosis, hyper-triglyceridaemia, postprandial dyslipidemia. 


\section{Introduction}

Diabetes mellitus (DM) refers to a group of common metabolic disorders characterised by the distinct phenotype of hyperglycemia. The two broad categories of DM are designated as type 1 diabetes and type 2 diabetes. Both types of diabetes are preceded by the period of abnormal glucose homeostasis.

Type $2 \mathrm{DM}$ is preceded by a phase of abnormal glucose homeostasis defined as impaired fasting glucose (IFG) or impaired glucose tolerance (IGT). Dyslipidemia that is associated with type 2 diabetes plays a vital role in the pathogenesis of accelerated atherosclerosis in that population. The most important features of this dyslipidemia include an elevated very low density lipoproteins (VLDL) and total triglycerides (TGs) and a decreased high density lipoproteins (HDL) concentration in the serum. While fasting hyper triglyceridemia plays an important role in atherosclerosis, particularly in people with diabetes mellitus, this association has been less consistent and fasting HDL-C appears to be a far more significant determinant of atherosclerosis. However, when TGs are analysed in the postprandial state, they emerge as an independent and stronger coronary risk factors than HDL-C.

Postprandial hypertriglyceridemia is shown to be associated with asymptomatic and symptomatic macrovascular disease in both normo- and hypertriglyceridemic groups and such abnormalities have been reported in people with type 2 diabetes and hence the increased risk of atherosclerosis among them, might therefore be correlated to the higher degree of postprandial triglyceridemia. Earlier studies clearly demonstrate the presence of hypertriglyceridemia in the postprandial state among the diabetic subjects, irrespective of whether fasting triglyceride levels were high or low.

It is not clearly known whether the patients with type 2 diabetes with macro vascular disease have greater abnormalities of the triglyceride metabolism in the post prandial state than those without.

\section{Aim}

To study the fasting and postprandial lipid abnormalities in Type $2 \mathrm{DM}$

\section{Objectives}

1. To assess the pattern of fasting and postprandial dyslipidemia in Type $2 \mathrm{DM}$

2. To compare the fasting and postprandial lipid profiles in Type $2 \mathrm{DM}$ and age cum sex matched Controls

\section{Materials and Methods}

This analytical study was conducted from Sep 2017 to Oct 2019. During this period, the 50 patients with Type2 DM and 50 age and sex matched healthy patients as controls in $\mathrm{RMMCH}$ has been studied.

\section{Inclusion Criteria}

All patients with Type $2 \mathrm{DM}$ and same age and sex matched healthy controls. Diabetes diagnosed according to American Diabetes Association Criteria.

- $F B S>=126 \mathrm{mg} / \mathrm{dl}, \mathrm{PPBS}>=200 \mathrm{mg} / \mathrm{dl}$.

- Total cholesterol $>200 \mathrm{mg} / \mathrm{dl}$

- Triglycerides $>150 \mathrm{mg} / \mathrm{dl}$

- Low density lipoprotein (LDL) $>100 \mathrm{mg} / \mathrm{dl}$

- High density lipoprotein (HDL) $<50 \mathrm{mg} / \mathrm{dl}$

- Very low density lipoprotein (VLDL) $>30 \mathrm{mg} / \mathrm{dl}$

- LDL/HDL ratio>3.5

\section{Exclusion Criteria}

- Type1 DM

- Medications that affect lipid levels

- Hepatic disease

- Hypothyroidism

- Nephrotic range proteinuria $>3 \mathrm{gms} /$ day

- Smoking

- Alcoholism

\section{Method of collection of data}

A detailed proforma was filled up for each patient, which included age, sex, IP number, detailed 
history, past and personal history, medication history. A detailed clinical examination was done. Laboratory parameters including fasting and postprandial blood glucose, renal function tests, liver function tests, ECG and routine urine examination. Fasting and Post prandial lipid profile which included serum total cholesterol, serum triglycerides, LDL cholesterol, HDL cholesterol and VLDL were estimated in all the cases and controls. Blood was collected from patients after an overnight (12-hour) fast and six- hour postprandial (after a standard meal) forlipid profile measurements.

\section{Statistical Analysis}

The following statistical methods were employed

1. Descriptive statistics

2. T test - Independent samples

3. T test pair samples

4. Repeated measure ANOVA

5. Product-moment correlation

Using SPSS for windows

\section{Results}

Age distribution of the cases and controls

\begin{tabular}{|c|c|c|c|c|c|}
\hline \multirow{2}{*}{ Age } & \multicolumn{2}{|c|}{ Control } & \multicolumn{2}{c|}{ Diabetic } & \multirow{2}{*}{ Total } \\
\cline { 2 - 5 } & $\mathbf{N}$ & $\mathbf{\%}$ & $\mathbf{N}$ & $\boldsymbol{\%}$ & \\
\hline $31-40$ & 6 & 12 & 2 & 4 & 8 \\
\hline $41-50$ & 17 & 34 & 11 & 22 & 28 \\
\hline $51-60$ & 14 & 28 & 14 & 28 & 28 \\
\hline $61-70$ & 9 & 18 & 17 & 34 & 26 \\
\hline$>71$ & 4 & 8 & 6 & 12 & 10 \\
\hline Total & 50 & 100 & 50 & 100 & 100 \\
\hline
\end{tabular}

Showing the age distribution of the cases and controls

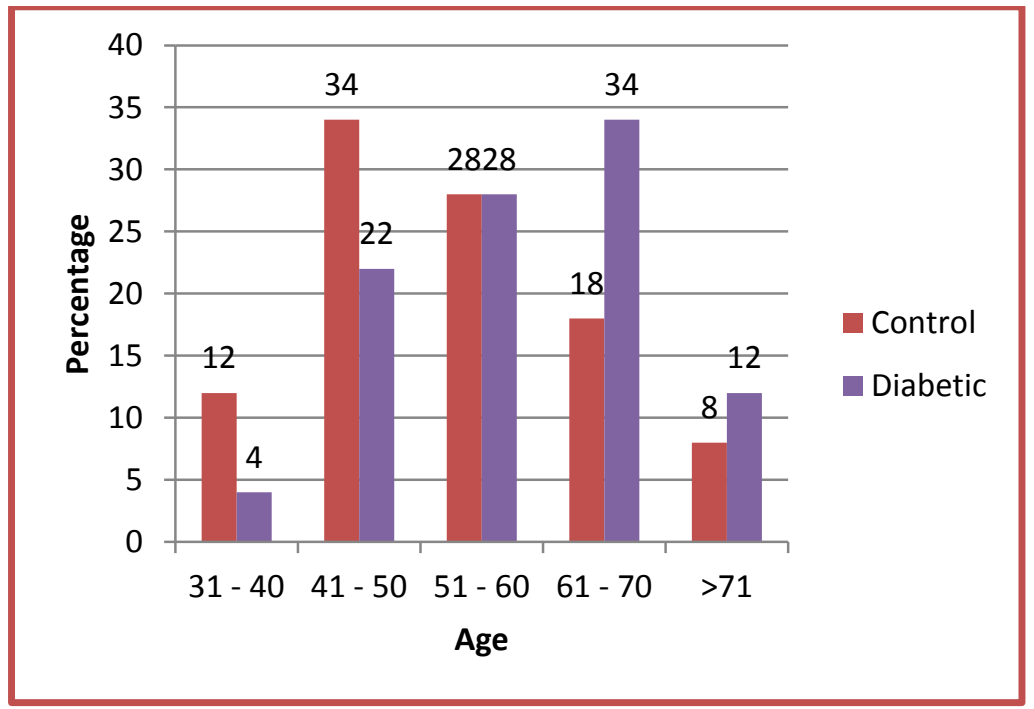

The majority of cases were in the age group of 61-70 years.

Sex wise distribution of the cases and controls

\begin{tabular}{|c|c|c|c|c|c|}
\hline \multirow{2}{*}{ Sex } & \multicolumn{2}{|c|}{ Control } & \multicolumn{2}{c|}{ Diabetic } & \multirow{2}{*}{ Total } \\
\cline { 2 - 5 } & $\mathbf{N}$ & $\mathbf{\%}$ & $\mathbf{N}$ & $\mathbf{\%}$ & \\
\hline Male & 30 & 60 & 30 & 60 & 60 \\
\hline Female & 20 & 40 & 20 & 40 & 40 \\
\hline Total & 50 & 100 & 50 & 100 & 100 \\
\hline
\end{tabular}




\section{JMSCR Vol||07||Issue $\| 10||$ Page 715-724||October}

Showing the sex wise distribution of the cases and controls

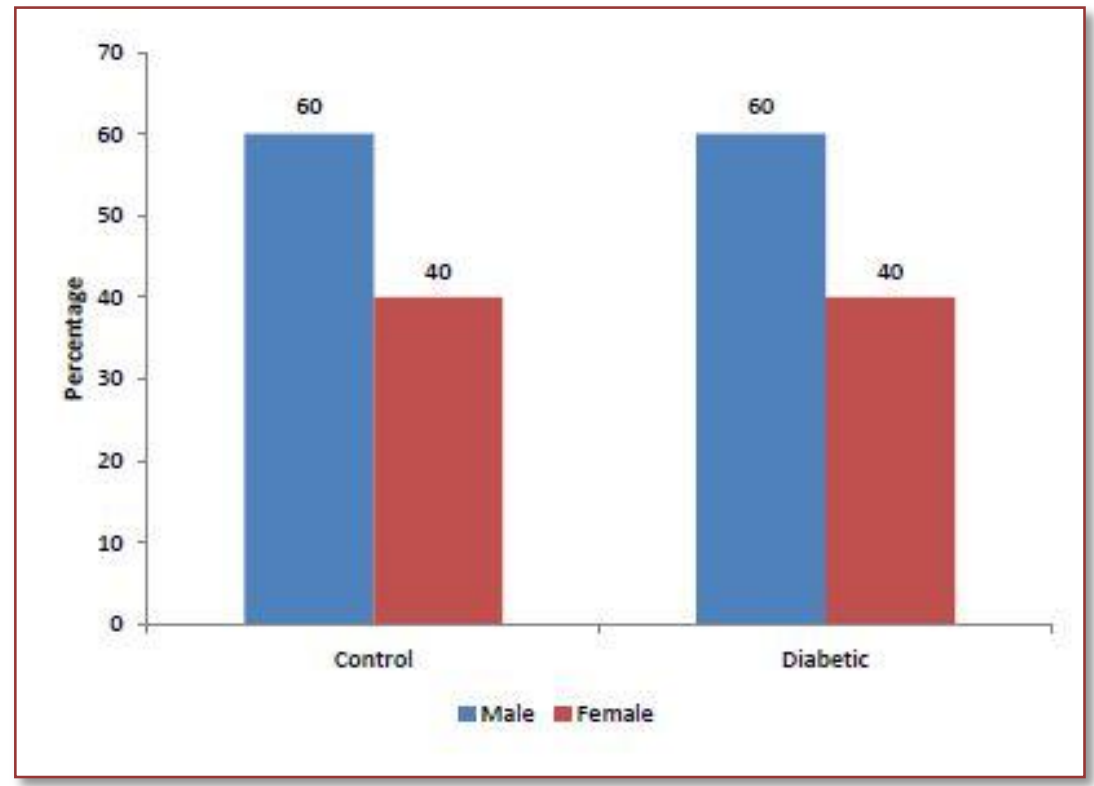

In this study, 60 percent were males and 40 percent were females, in both the groups.

Duration of diabetes among the study group

\begin{tabular}{|c|c|c|c|c|c|}
\hline \multirow{2}{*}{ DM } & \multicolumn{2}{|c|}{ Control } & \multicolumn{2}{c|}{ Diabetic } & \multirow{2}{*}{ Total } \\
\cline { 2 - 5 } & $\mathbf{N}$ & $\mathbf{\%}$ & $\mathbf{N}$ & $\boldsymbol{\%}$ & - \\
\hline No Diabetes & 50 & 100 & - & - & - \\
\hline Newly detected & - & - & 4 & 8 & 54 \\
\hline $1-5$ & - & - & 14 & 28 & 14 \\
\hline $6-10$ & - & - & 26 & 52 & 26 \\
\hline Above 10 & - & - & 6 & 12 & 6 \\
\hline Total & 50 & 100 & 50 & 100 & 100 \\
\hline
\end{tabular}

Graph showing the duration of diabetes among the study group

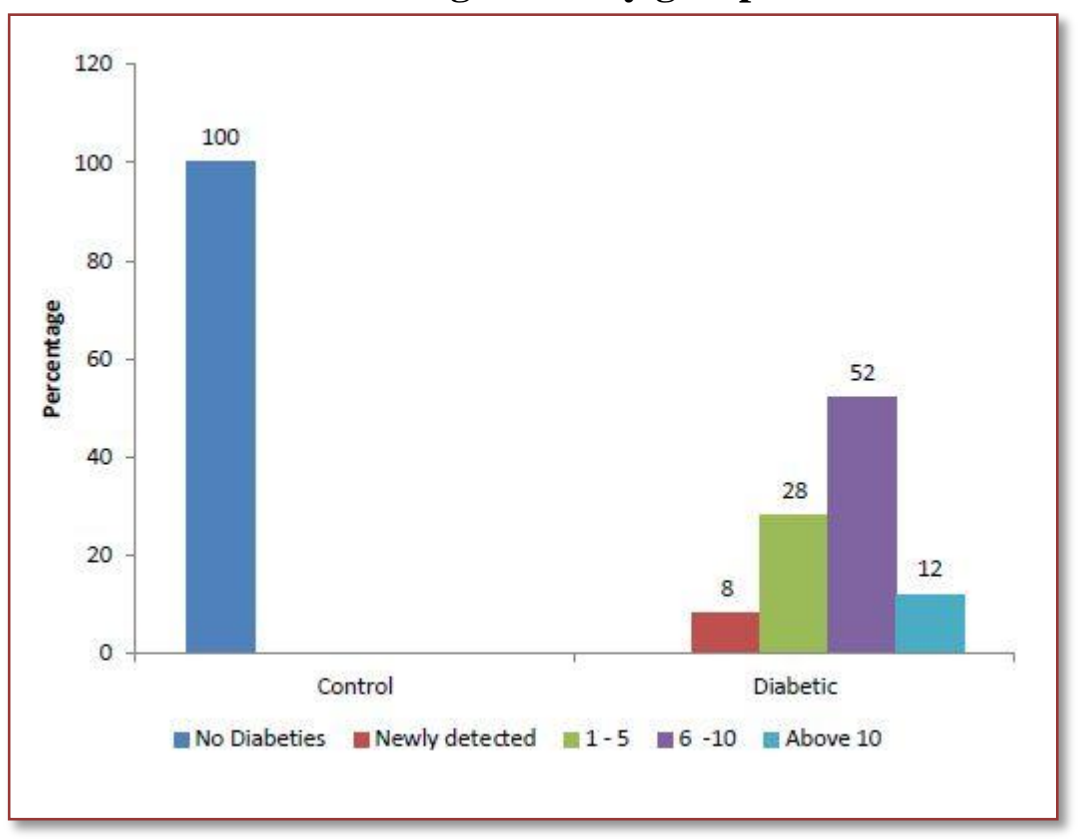


In this study $8 \%$ of the cases were newly detected type 2 diabetics, whereas $28 \%$ of the cases had diabetes for 1 - 5 years, $52 \%$ had diabetes for $6-$
10 years and $12 \%$ had diabetes for more than 10 years. In the control group none of the patients had type 2 diabetes mellitus.

\section{Duration of hypertension among the study group}

\begin{tabular}{|c|c|c|c|c|c|}
\hline \multirow{2}{*}{ HTN } & \multicolumn{2}{|c|}{ Control } & \multicolumn{2}{c|}{ Diabetic } & \multirow{2}{*}{ Total } \\
\cline { 2 - 5 } & $\mathbf{N}$ & $\mathbf{\%}$ & $\mathbf{N}$ & $\mathbf{\%}$ & \\
\hline No HTN & 50 & 100 & 30 & 60 & 80 \\
\hline $1-5$ & - & - & 7 & 14 & 7 \\
\hline Above 5 & - & - & 13 & 26 & 13 \\
\hline Total & 50 & 100 & 50 & 100 & 100 \\
\hline
\end{tabular}

Graph showing the duration of hypertension among the study group

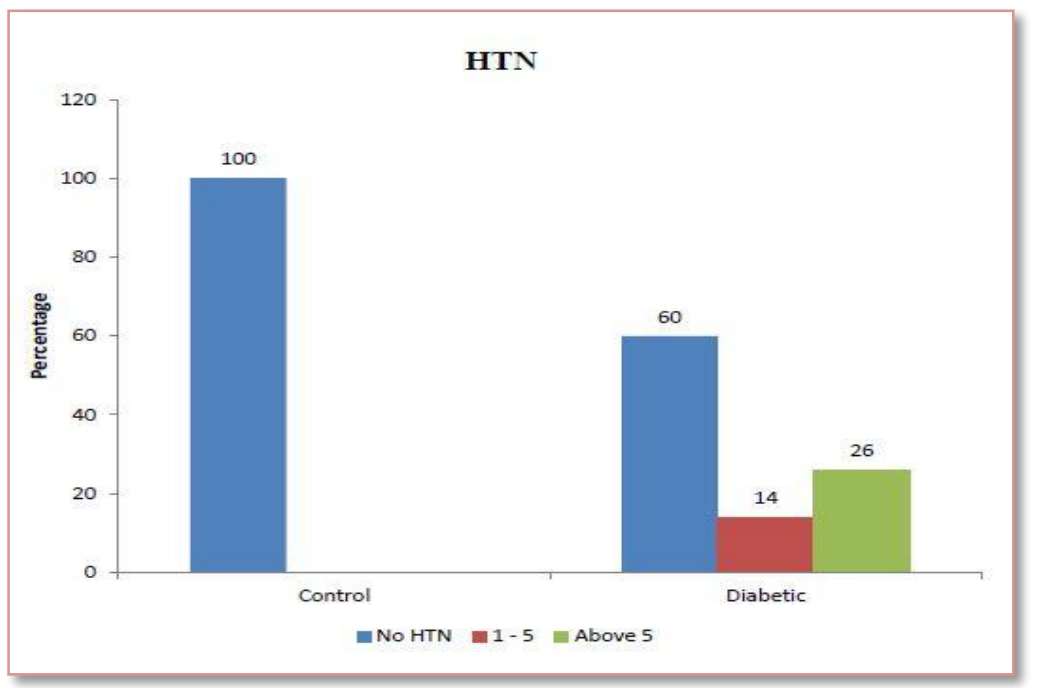

In this study, $40 \%$ of diabetics had hypertension whereas $60 \%$ of diabetics were normotensive. None of the controls, were found to have hypertension.

Comparison of the mean fasting and post prandial total Cholesterol levels among the cases and controls

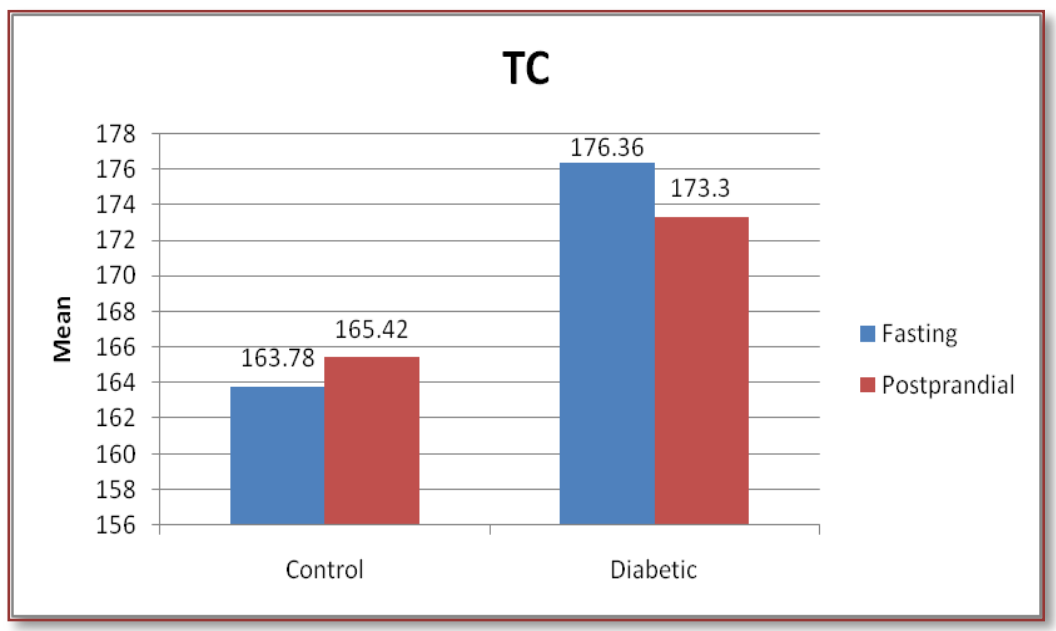

There was no significant difference in the TC level in the cases compared to that of the controls in both the fasting and post prandial state. 
Comparison of the mean fasting and post prandial LDL-C levels among the cases and controls

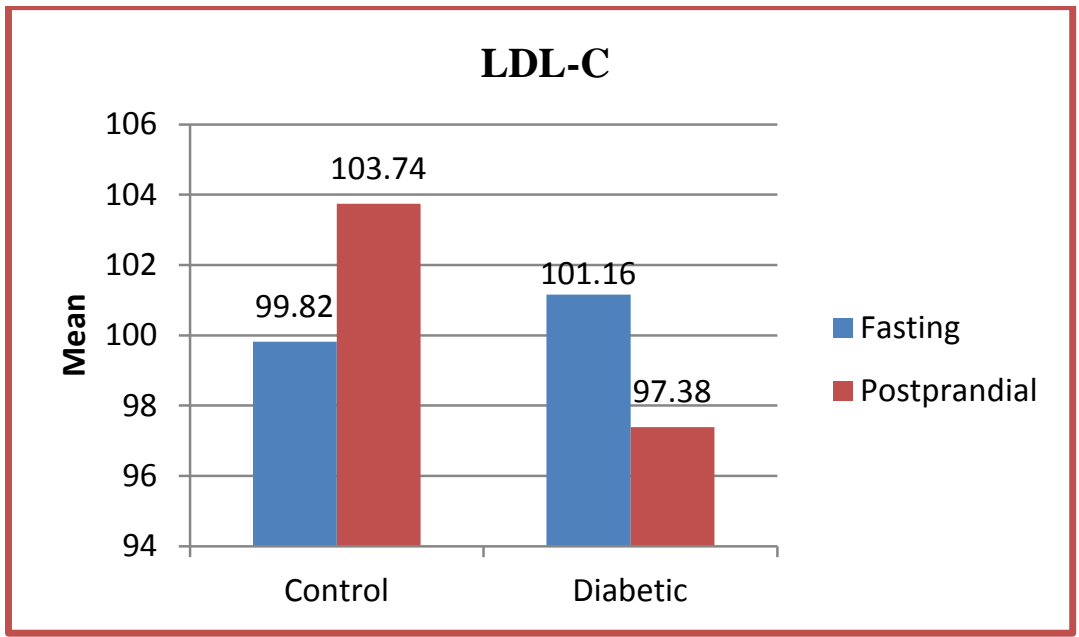

There was a no significant increase in the LDL-C level among the cases compared to that of the controls in both the fasting and post prandial state.

Comparison of the mean fasting and post prandial VLDL-levels among the cases and controls

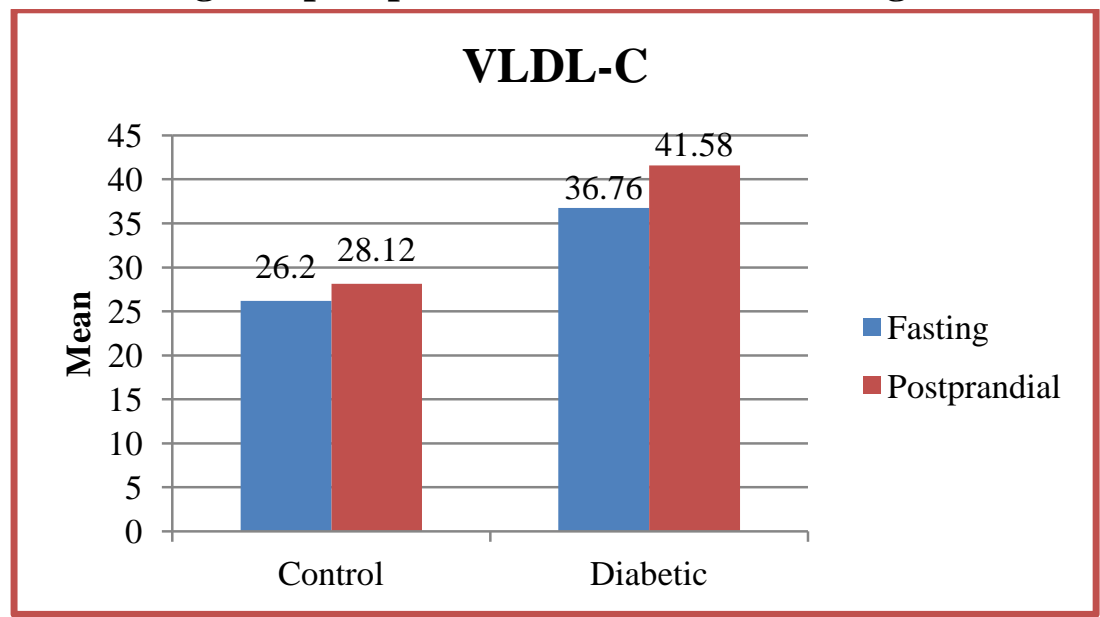

The cases with diabetes were found to have elevated VLDL-C levels when compared with that of controls in both fasting and post prandial.

Comparison of the mean fasting and post prandial triglyceride levels among the cases and controls

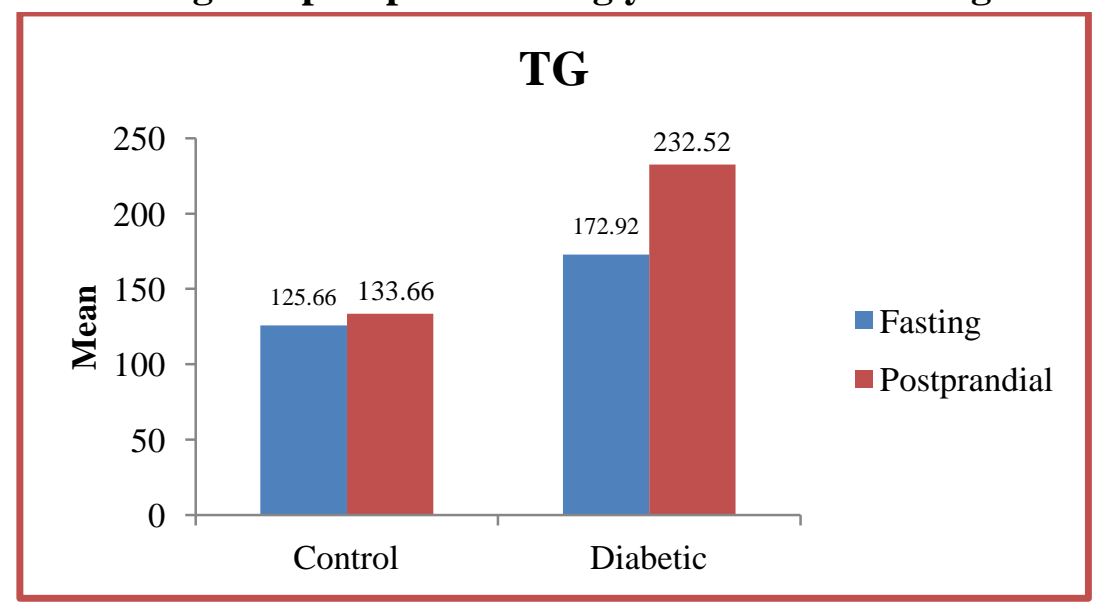

In the fasting state cases with diabetes were found to have elevated triglyceride levels when compared with that of controls. There was a significant increase in the post prandial TG level in patients with diabetes. 
Comparison of the mean fasting and post prandial HDL-C levels among the cases and controls

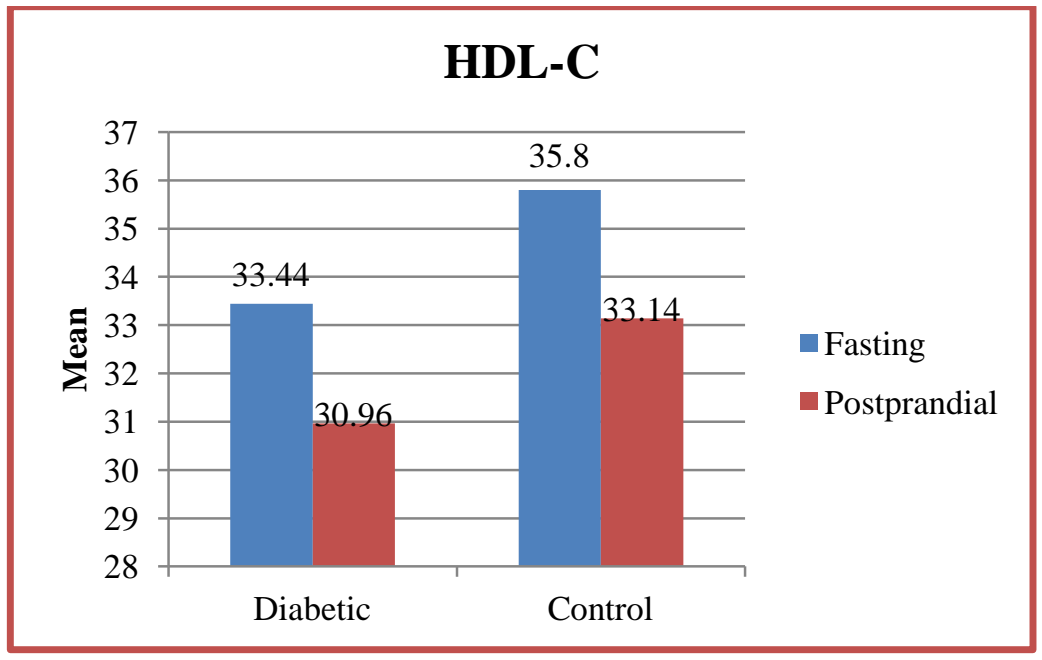

Though the HDL-C levels in diabetics was low, there was no significant difference in the HDL$\mathrm{C}$ levels in both the cases and controls in the fasting state. In the post prandial state, there was a significant decrease in the HDL-C level in the cases compared to that of the controls.

\section{Comparison of the mean fasting and post prandial lipid levels among the cases and controls}

\begin{tabular}{|c|c|c|c|c|c|c|}
\hline & & Group & $\mathbf{N}$ & Mean & SD & $\mathbf{P}$ \\
\hline \multirow{10}{*}{ 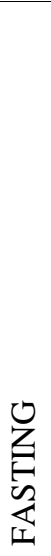 } & \multirow{2}{*}{$\mathrm{TC}$} & Control & 50 & 163.78 & 36.29 & \multirow{2}{*}{0.166} \\
\hline & & Diabetic & 50 & 176.36 & 52.43 & \\
\hline & \multirow{2}{*}{ HDL-C } & Control & 50 & 35.80 & 11.42 & \multirow{2}{*}{0.316} \\
\hline & & Diabetic & 50 & 33.44 & 11.99 & \\
\hline & \multirow{2}{*}{ LDL-C } & Control & 50 & 99.82 & 36.21 & \multirow{2}{*}{0.857} \\
\hline & & Diabetic & 50 & 101.16 & 38.17 & \\
\hline & \multirow{2}{*}{ VLDL-C } & Control & 50 & 26.20 & 13.41 & \multirow{2}{*}{0.003} \\
\hline & & Diabetic & 50 & 36.76 & 20.01 & \\
\hline & \multirow{2}{*}{ TG } & Control & 50 & 125.66 & 49.55 & \multirow{2}{*}{0.000} \\
\hline & & Diabetic & 50 & 172.92 & 75.51 & \\
\hline \multirow{10}{*}{ 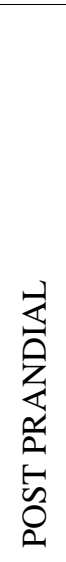 } & \multirow{2}{*}{$\mathrm{TC}$} & Control & 50 & 165.42 & 35.36 & \multirow{2}{*}{0.323} \\
\hline & & Diabetic & 50 & 173.30 & 43.56 & \\
\hline & \multirow{2}{*}{ HDL-C } & Control & 50 & 33.14 & 11.04 & \multirow{2}{*}{0.04} \\
\hline & & Diabetic & 50 & 30.96 & 11.15 & \\
\hline & \multirow{2}{*}{ LDL-C } & Control & 50 & 103.74 & 35.60 & \multirow{2}{*}{0.383} \\
\hline & & Diabetic & 50 & 97.38 & 36.93 & \\
\hline & \multirow{2}{*}{ VLDL-C } & Control & 50 & 28.12 & 14.00 & \multirow{2}{*}{0.000} \\
\hline & & Diabetic & 50 & 41.58 & 19.82 & \\
\hline & \multirow{2}{*}{ TG } & Control & 50 & 133.66 & 48.79 & \multirow{2}{*}{0.000} \\
\hline & & Diabetic & 50 & 232.52 & 105.08 & \\
\hline
\end{tabular}

\section{Discussion}

In the present study, fasting and post prandial lipid profile was done in 50 patients with type 2 diabetes mellitus and was compared with the fasting and post prandial lipid profile in 50 healthy controls, age and sex matched, fulfilling the inclusion and exclusion criteria. 
Age distribution of cases and controls

In the present study, the study group constituted cases from age 31 to 85 years. The majority of cases were in the age group of 61-70 years which constituted $34 \%$ of the total; Followed by persons in the age group 51-60 years who constituted $28 \%$ of the total study.

\section{Sex wise distribution of the cases and controls}

In this study, $60 \%$ of the study group were males and $40 \%$ of the study group were females. Similarly the control group consisted of 60\% males and $40 \%$ females age matched with the study group.

\section{Duration of diabetes among the study group}

In this study $8 \%$ of the cases were newly detected with type 2 diabetes mellitus. The duration of diabetes in $28 \%$ of cases was between 1 - 5 years, $52 \%$ between 6- 10 years and $12 \%$ of cases had diabetes for more than 10 years. In the control group none of the patients had diabetes.

\section{Prevalence of hypertension among the study group}

In the present study, the prevalence of hypertension among the cases was $40 \%$ and among the controls none of them had hypertension. In the study done by Sumesh raj et al the prevalence of hypertension was seen to be significantly higher in the cases $(28 \%)$, which is consistent with our study.

Total Cholesterol levels among the cases and controls

In this study, in the fasting state, $24 \%$ of cases had total cholesterol levels of $>200 \mathrm{mg} / \mathrm{dl}$ as compared with the controls where $16 \%$ of them had total cholesterol of $>200 \mathrm{mg} / \mathrm{dl}$. This association has a $\mathrm{p}$ value of 0.146 , which is statistically not significant. There was no significant increase in the post prandial TC level in the cases compared to that of the controls. Similar observations were made in the studies done by SV Madhu et al.

\section{LDL-C levels among the cases and controls}

In this study, in the fasting state, $58 \%$ of cases had LDL-C levels of $<100 \mathrm{mg} / \mathrm{dl}$ as compared with that of the control group where $46 \%$ of controls had LDL-C of $<100 \mathrm{mg} / \mathrm{dl}$. This association has a $p$ value of 0.266 , which is statistically not significant.

In the Strong Heart Study done by Howard BV et al it was shown that, in American Indians, LDL cholesterol level was the most significant predictor of increased CHD, despite an average LDL cholesterol level of approximately $115 \mathrm{mg} / \mathrm{dL}$ in diabetics. In the same study, LDL was a strong predictor of CHD at levels as low as $70 \mathrm{mg} / \mathrm{dl}$.

In our study though the diabetics had a decreased LDL-C in the post prandial state, it was statistically insignificant. This does not correlate with a study done by Lund et al which showed that in diabetics, LDL-C decreased significantly post prandially ( $\mathrm{p}<0.005)$.

\section{VLDL-C levels among the cases and controls}

In this study, in the fasting state $28 \%$ of cases had total VLDL-C levels of $>40 \mathrm{mg} / \mathrm{dl}$ as compared with that of the control group where only $8 \%$ of them had VLDL-C levels of $>40 \mathrm{mg} / \mathrm{dl}$. This association has $\mathrm{p}$ value of 0.029 which is statistically significant. Thus cases with diabetes were found to have elevated VLDL-C levels when compared with that of controls. This correlates with the study done by Angela A Rivellese et al.

Similarly, in the post prandial state, $46 \%$ of cases had VLDL-C levels of $>40 \mathrm{mg} / \mathrm{dl}$ as compared with that of control group, where $14 \%$ of them had VLDL-C levels of $>40 \mathrm{mg} / \mathrm{dl}$. This association has a p value of 0.001 which is statistically significant. Thus cases with diabetes were found to have elevated post prandial VLDL-C levels when compared with that of controls .This does not correlate with the study done by Angela A Rivellese et al.

Triglyceride levels among the cases and controls

In this study, in the fasting state $56 \%$ of the cases had total TG levels of $>150 \mathrm{mg} / \mathrm{dl}$ as compared with that of control group wherein only $30 \%$ of them had TG levels of $>150 \mathrm{mg} / \mathrm{dl}$. This association has a $\mathrm{p}$ value of 0.021 , which is statistically significant. 
Thus in the fasting state cases with diabetes were found to have elevated triglyceride levels when compared with that of the controls. This correlates with the studies done by Sumesh raj et al, SV Madhu et al \& Angela A Rivellese et al.

There was a significant increase in the post prandial TG level in the cases compared to that of the controls. Similar observations were made in the studies done by SV Madhu et al, Sumesh raj et al ( $\mathrm{p}<0.01)$, \& Angela A Rivellese et al.

\section{HDL-C levels among the cases and controls}

In this study, in the fasting state $70 \%$ of the cases had HDL-C levels of $<35 \mathrm{mg} / \mathrm{dl}$ as compared with that of control group wherein $60 \%$ of them had HDL-C levels of $<35 \mathrm{mg} / \mathrm{dl}$.

This association has a $\mathrm{p}$ value $>0.05$, which is not significant. Hence, there was no significant difference in the HDL-C levels in both the cases in the fasting state. This correlates with the study done by Sumesh raj et al which showed no significant difference in the HDL-C levels in the diabetics and controls. This does not correlate with the study done by SV Madhu et al which showed that diabetics had lower HDL-C levels compared to that of the controls.

This association has a $p$ value of 0.04 for post prandial state which is statistically significant. Hence, there was a significant decrease in the post prandial HDL-C level in the cases compared to that of the controls. Similar observations were made in the studies done by SV Madhu et al.

\section{Conclusion}

- The dyslipidemia of Type $2 \mathrm{DM}$ is characterized mainly by raised triglyceride levels, raised VLDL-C Levels and decreased HDL-C levels.

- In the post prandial state there was significant hyper-triglyceridaemia and decreased HDL-C levels in diabetics when compared to that of the control.

\section{References}

1. Peter A. Mayes, Kathleen M. Botham. Lipids of physiologic significance. Robert K. Murray, Daryl K. Granner, Peter A. Mayes, Victor W Rodwell Editors. In Harper's Illustrated Biochemistry: $26^{\text {th }}$ Edition Mcgraw Hill, USA 121-132

2. Robert W. Mahley, Karl H. Weisgraber, Thomas P. Bersot. Disorders of lipid metabolism. Henry M. Kronenberg, Shlomo Melmed, Kenneth S. Polonsky, Reed Larsen $\mathrm{P}$ Editors. In Williams Textbook of Endocrinology; $11^{\text {th }}$ edition: Saunders Elsevier, Philadelphia, 15891655.

3. Barbara V Howard, James Howard Wm. Pathophysiology and treatment of lipiddisorders in diabetes. Ronald Kahn C, George L King Alan C Moses, Gordon C Weir, Alan M Jacobson, Robert J Smith Editors. In Joslin's Diabetes mellitus: 14th edition: lippincott, philedelphia, 563-79.

4. Hussain MM, Fatma S, Pan X, Iqbal J: Intestinal lipoprotein assembly. CurrOpin Lipidol 2005; 16:281-285.

5. Mahley RW, Huang Y, Rall Jr SC: Pathogenesis of type III hyperlipoproteinemia (dysbetalipoproteinemia). questions, quandaries, and paradoxes. J Lipid Res 2005; 16:281-285.

6. Mahley RW, Rall Jr SC: Type III hyperlipoproteinemia

(dysbetalipoproteinemia). The role of apolipoprotein $\mathrm{E}$ in normal and abnormal lipid metabolism. In: Scriver CR, Beaudet AL, Sly WS, ed. The Metabolic and Molecular Bases of Inherited Disease, vol 2. $8^{\text {th }}$ ed. New York: McGraw- Hill; 2001:2835-2862.

7. Mahley RW, Ji Z-S: Remnant lipoprotein metabolism. Key pathways involving cell-surface heparan sulfate proteoglycans and apolipoprotein E. J Lipid Res 1999; 40:1-16. 
8. Mahley RW. Biochemistry and physiology of lipid and lipoprotein metabolism. In Becker KL [ed]. Principles and Practice of Endocrinology and Metabolism, Philadelphia. JB Lippincott 1995:1369-1378.

9. Havel RJ, Kane JP: Introduction. Structure and metabolism of plasma lipoproteins. In: Scriver CR, Beaudet AL, Sly WS, ed. The Metabolic and Molecular Bases of Inherited Disease, vol 2. 8th ed. New York: McGraw - Hill; 2001:27052716.

10. Tsai L-Y, Tsai S-M, Lee S-C, Liu SF: Falsely low LDL-cholesterol concentrations and artifactual undetectable HDL-cholesterol measured by direct methods in a patient with monoclonal paraprotein. Clin Chim Acta 2005; 358:192-195.

11. Disorders of lipoprotein metabolism. In: Longo DL, Fauci AS, Kasper DL, Hauser SL, Jameson JL, Loscalzo J. Eds. Harrison's Principles Of Internal Medicine: New York, Mcgraw Hill.

12. Sumesh Raj, Rajasekharan C, Jayakumar B. Postprandial hypertriglyceridemia in type 2 diabetic subjects. IJDDC 2006; 26 : 160-162

13. Madhu SV, Mittal V, Krishna Ram B, Srivastava DK. Postprandial lipid abnormalities in type 2 diabetes mellitus 2005; 53: 1043-1046

14. Howard BV, Robbins DC, Sievers ML, et al. LDL cholesterol as a strong predictor of coronary heart disease in diabetic individuals with insulin resistance and low LDL: the Strong Heart Study. Arterioscler Thromb Vasc Biol 2000; 20:830-835.

15. Lund S. S, Petersen M. ; Frandsen M. Sustained postprandial decrease in plasma levels of LDL cholesterol in patients with type-2 diabetes mellitus. Scand J clin lab invest 2008; 68(7) : 628-638.
16. Rivellese AA, De Natale C, Di Marino L et al. Exogenous and endogenous postprandial lipid abnormalities in type 2 diabetic patients with optimal blood glucose control and optimal fasting triglyceride levels. J Clin Endocrinol Metab 2004; 89(5): 2153-9. 